DOI: http://dx.doi.org/10.18203/2320-1770.ijrcog20181952

Case Report

\title{
Caesarean scar ectopic pregnancy
}

\section{T. Ramani Devi*, T. Sweta, C. Archana Devi,}

${ }^{1}$ Department of Obstetrics and Gynecology, Ramakrishna Nursing Home and Janani Fertility Centre, Trichy, Tamil Nadu, India

Received: 09 February 2018

Accepted: 07 March 2018

\section{*Correspondence:}

Dr. T Ramani Devi,

E-mail: ramanidevirmc@gmail.com

Copyright: (c) the author(s), publisher and licensee Medip Academy. This is an open-access article distributed under the terms of the Creative Commons Attribution Non-Commercial License, which permits unrestricted non-commercial use, distribution, and reproduction in any medium, provided the original work is properly cited.

\begin{abstract}
Ectopic pregnancy is a common cause of mortality and morbidity among the women of reproductive age group. Tubal pregnancy is the commonest. It can occur in cervix, ovaries, previous caesarean scar, interstitial portion of the tube and abdominal cavity. Here we report a case of caesarean scar ectopic pregnancy which was managed conservatively. 31 yrs old gravid 3 previous 1 LSCS and 1 tubal ectopic come for antenatal consultation at 35 days of gestation. UPT was Positive. USG showed no evidence of intra uterine sac. Repeat scan after 10 days showed a gestational sac at the lower uterine segment scar. Hence it was decided for conservative management, injection methotrexate $50 \mathrm{mgm} \mathrm{X} 2$ doses given. This was followed by misoprost vaginal insertion. Since patient did not expel the sac, injection PG F2 alpha $125 \mathrm{mg} \times 2$ doses were given. Patient expelled the products of conception partially. This was followed by hysteroscopic guided evacuation.Caesarean scar ectopic was reported in 1978. Early diagnosis is by TV USG / MRI. Early ectopic can be treated medically. In delayed diagnosis, laparoscopic excision of the scar has to be done. In rupture of the scar site ectopic pregnancy laparotomy is indicated. In the event of heavy bleeding, hysterectomy has to be done. After conservative management and excision of the scar, fertility is not altered.

Conclusion: Caesarean section scar pregnancy is a rare form of ectopic pregnancy which can lead to life threatening complications leading to mortality and morbidity. Treatment has to be individualized according to the gestational age, haemodynamic stability and desire for future fertility.
\end{abstract}

Key words: Case report, Caesarean, Ectopic pregnancy scar, Women

\section{INTRODUCTION}

Ectopic pregnancy is one of the leading causes of mortality and morbidity among the women of reproductive age group. Tubal ectopic pregnancy is the commonest, however it can rarely occur in cervix, ovaries, previous caesarean scar, interstitial portion of the tube and abdominal cavity. Caesarean scar ectopic is defined as the presence of gestational sac implanted at the site of previous caesarean scar. It is one of the rarest types of ectopic pregnancy. ${ }^{1}$

First case was reported in $1978 .^{2}$ It mostly occurs in women who had more than 2 LSCS. It has an estimated incidence of 1:1800 - 2200 pregnancies., ${ }^{3,4}$ The overall incidence is however thought to be increasing, representing up to $6 \%$ of the ectopic pregnancies. Recurrence rate is $5 \%$. This could be due to the increase in number of multiple caesarean sections. ${ }^{1}$ Wide spread use of TV USG helps to detect caesarean scar ectopic pregnancy.

It is life threatening, if undetected or misdiagnosed and can cause serious maternal morbidity from uterine rupture and massive haemorrhage leading to hypovolemic shock and even mortality. Here we present a case of ectopic pregnancy in previous C-Section scar detected very early and treated conservatively. 


\section{CASE REPORT}

31 yrs old, gravida 3 with previous 1 LSCS followed by 1 tubal ectopic pregnancy which was managed medically, came for the antenatal consultation on 30.1216 . Her LMP was on 25/11/16 and UPT was positive. TV USG was done which showed absence of intra uterine gestational sac and adnexal mass.

Beta HCG was done on $31 / 12 / 16$ and the value was $6418 \mathrm{miu} / \mathrm{ml}$. It was repeated on $9 / 1 / 17$ and the value was $10551 \mathrm{miu} / \mathrm{ml}$ and the raise in HCG was not suggestive of intra uterine pregnancy.

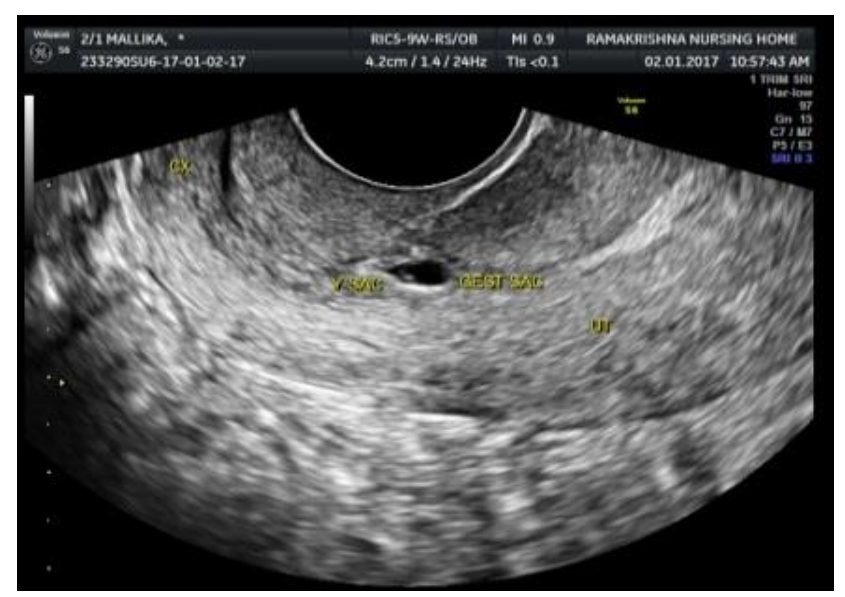

Figure 1: USG on 02.01.2017.

USG was repeated on 9.1.17 and in the findings were suggestive of caesarean scar ectopic pregnancy. Both uterine cavity and cervical canal were empty, and the gestational sac was seen in the anterior myometrium of the lower uterine segment scar. Only yolk sac was seen and there was no fetal pole. Chorio decidual reaction was good with good vascularity confirming the diagnosis of caesarean scar ectopic pregnancy. MRI was not done for this patient, though this will be of valuable help in doubtful cases.

Again, this patient had a previous tubal pregnancy which was also managed medically in our centre.

Since, she had only one live baby and it was an early sac, she was treated conservatively with 2 doses of IM injection of Methotrexate $50 \mathrm{mgm}$ per day on alternate days. After 7 days repeat scan showed persistent sac with no FHR and reduced vascularity. Hence, T.Misoprost 200mic gms kept vaginally and repeated 4 hours later. Patient did not expel the products of conception.

Hence Prostaglandins F2 alpha 125 mgms was given IM (2doses at 1hour gap). She expelled the products partially. USG showed retained products and hence hysteroscopic guided $\mathrm{D}$ and $\mathrm{C}$ was done. There was no bleeding and the procedure was uneventful. Repeat USG showed a normal uterus.

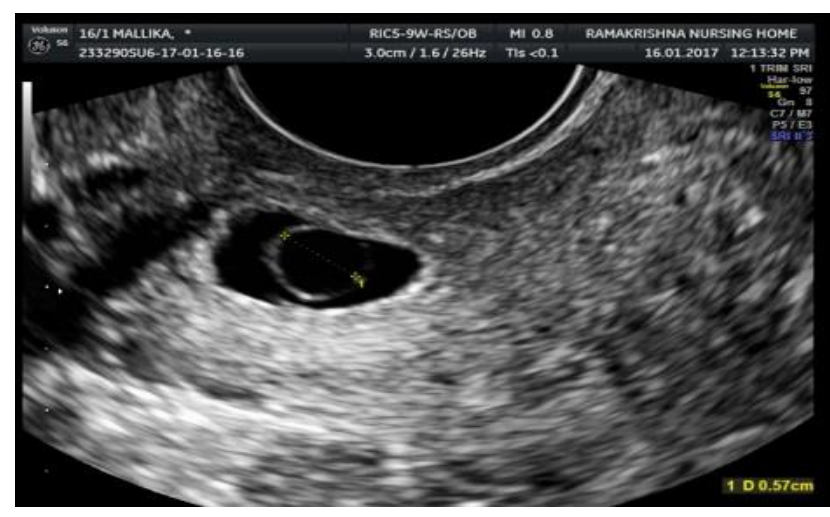

Figure 2: USG on 02.01.2017.

\section{DISCUSSION}

Ectopic pregnancy in caesarean scar was first reported in 1978 by Larson and Solomon. ${ }^{2}$ Women with previous multiple caesarean section scars are at increased risk of scar ectopic pregnancy. ${ }^{5}$ It should be diagnosed as early as possible in order to avoid severe complications like scar rupture and intra peritoneal bleed. Early diagnosis will help for conservative management. The most common symptom will be painless vaginal bleeding, which may be massive and life threatening. At times the patient may be posted for surgical termination which can cause profuse bleeding. Spontaneous miscarriage can happen in $44 \%$ of the patients.

Vial et al has suggested that there are two different types of pathologies for caesarean scar ectopic pregnancies. In the first one, the pregnancy grows towards the uterine cavity. This can lead to a term viable baby but there is always a risk placenta previa and accreta. The second type can progress deep into the uterine scar towards the serosa which will lead to early rupture and bleeding. Here also placenta can be accreta or invade the bladder. The first type can be managed expectantly and the second one needs emergency care. Hence, these women should be counselled accordingly. Maymon et al believed uneventful term pregnancy is quiet rare.

Diagnosis is often difficult but early diagnosis is possible with TV USG and colour doppler. In doubtful cases, MRI might give more accurate information but not always mandatory. ${ }^{6,7}$ TV USG is highly sensitive in diagnosis of caesarean scar site pregnancy with the sensitivity of $86.4 \% .^{2,8}$

Sonographic criteria for diagnosis of pregnancy in scar are:

- Empty uterus

- Empty cervical canal 
- Gestational sac located in anterior part of the isthmic portion of uterus with a diminished myometrial layer between bladder and sac.

- Discontinuity in the anterior wall of the uterus. There should be clearly visible blood flow surrounding the sac. Mainly it has to be differentiated from cervical ectopic pregnancy. Differential diagnosis includes cervical ectopic pregnancy and placenta accrete. ${ }^{9}$

Jurkovic has described a negative sliding organ sign as diagnostic of scar ectopic. It is the inability to displace the gestational sac from its position at the level of internal or by gentle pressure applied by trans abdominal probe. ${ }^{10}$

With the use of TV USG and saline infusion, it is possible to assess post caesarean section uterine wall integrity even in non-pregnant patients. It can be identified by the presence of fluid within the incision site or filling defect (niche) which is a triangular anechoic structure at the site of scar. ${ }^{4,7}$ These patients should be watched for caesarean scar ectopic pregnancy in the future. Several types of conservative treatment have been proposed. Local or systemic Methotrexate and intra lesion and potassium chloride administration. ${ }^{3,9}$

There may be delay in the resorption of the pregnancy because of the fibrous scar rather than normal vascularized decidua. There may be failure in the management with systemic Methotrexate if Beta HCG is greater than $5000 \mathrm{miu} / \mathrm{ml}$ and in these cases better response can be seen with intra lesional methotrexate. ${ }^{11}$ This can also be conservatively managed USG guided aspiration rarely rupture of the scar and heavy bleeding can happen after medical management. ${ }^{12}$ Hence, approach can be combined with bilateral uterine artery embolization to reduce the life threatening haemorrhage.

Surgical management is indicated in greater gestational age or when medical management fails. Excision of the sac through laparoscopy or laparotomy which includes excision of the scar site ectopic and closure of the scar. ${ }^{4,7}$ Bilateral hypogastric artery ligations followed by dilatation and evacuation under laparoscopic guidance may be another alternative. ${ }^{9,7}$ In cases of massive bleed emergency hysterectomy is lifesaving. Hysteroscopy is a minimally invasive approach that includes visualizing the uterine cavity combined with evacuation of the ectopic mass.

Our patient received IM methotrexate followed by T.Misporostal vaginally and IM prostoglandins, after which she expelled the products of conception partially followed by hysteroscopic guided D and C. The reason for failure of IM methotrexate could be the initial level of beta HCG which was greater than $5000 \mathrm{miu} / \mathrm{ml}$. Immediate complications of $\mathrm{C}$-section scar pregnancy are uterine rupture, severe bleeding and need for hysterectomy leading maternal morbidity and rarely mortality.
After conservative treatment, further fertility is not affected, and the patient has to be watched for recurrence of caesarean scar pregnancy.

\section{CONCLUSION}

Caesarean scar pregnancy is a rare form of ectopic pregnancy which can lead to life threatening complications. It can be diagnosed as early as in the first trimester, so that we can prevent maternal mortality and morbidity. Treatment should be planned to take into consideration the gestational age, haemodynamic status of the patient, absence or presence of scar rupture, HCG levels, and desire for further fertility.

\section{Funding: No funding sources \\ Conflict of interest: None declared \\ Ethical approval: Not required}

\section{REFERENCES}

1. Maymon R, Halperin R, Mendlovic S, Schneider D, Herman A. Ectopic pregnancies in a Caesarean scar: review of the medical approach to an iatrogenic complication. Hum Reprod Update. 2004;10(6):51523.

2. Ash A, Smith A, Maxwell D. Caesarean scar pregnancy. BJOG. 2007;114(3):253-63.

3. Guindi WEl, Alalfy M, Abasy A, Ellithy A, Nabil A, Abdalfatah O. A Report of Four Cases of Caesarean Scar Pregnancy in a Period of 24 Months. J Med Diagn Meth. 2013;2(121):2.

4. Nankali A, Ataee M, Shah-lazadeh H and Daeichin S. Surgical Management of the Caesarean Scar Ectopic Pregnancy: A Case Report. Case Reports in Obst and Gynaecol. 2013; 1-5.

5. Fylstra DL. Ectopic pregnancy within caesarean Scar: a review. Obset Gynecol Surv.2002;57(8):53743.

6. Fatma MA and Ebtesam MF. Medical \& Clinical Reviews MRI in Caesarean Scar Ectopic Pregnancy. iMedPub Journals. 2015;1:1-9.

7. Aich R, Solanki N, Kakadiya K, Bansal A, Joshi M and Nawale A. Ectopic Pregnancy in caesarean section scar: A case report. Radiology Case Reports. 2015;10(4):68-71.

8. Wang CB,Tseng CJ.Primary evacuation therapy for caesarean scar pregnancy:three new cases and review .Ultrasound Obstet Gynecol. 2006;27(2):222-6.

9. Rizk B, Holiday CP, Owens S, Abuzeid M. Cervical and Caesarean scar ectopic pregnancies: Diagnosis and management. Middle East Fertility Society Journal. 2013;118(2):67-73.

10. Jurkovic D, Hillaby K, Woelfer B, Lawrence A, Salim R, Elson CJ. First-trimester diagnosis and management of pregnancies implanted into the lower uterine segment Cesarean section scar. Ultrasound Obstet Gynecol. 2003;21(3):220-7.

11. Ofili-Yebovi D, Ben-Nagi J, Sawyer E, Yazbek J, Lee C, Gonzalez J and Jurkovic D. Deficient lower- 
segment cesarean section scars: prevalence and risk factors. Ultrasound Obstet Gynecol. 2008:31(1):727.

12. Koplay M, Dogan NU, Sivri M, Erdogan H, Dogan S and Celik C. Ectopic Pregnancy in a Cesarean Section Scar: Successful Management Using Vacuum Aspiration under Laparoscopic Supervision
Mini Review of Current Literature. Case Reports Surg.2016;4

Cite this article as: Devi TR, Sweta T, Devi AC.

Caesarean scar ectopic pregnancy. Int J Reprod

Contracept Obstet Gynecol 2018;7:2038-41. 